\title{
Korean ESL Parents' Perspectives and Maintenance of Mother Tongue: A Case Study of Two Korean Mothers
}

\author{
Jaeseok Yang ${ }^{1}$ \\ ${ }^{1}$ Department of English Education, Daegu National University of Education, Daegu, South Korea \\ Correspondence: Jaeseok Yang, Department of English Education, Daegu National University of Education, \\ Daegu, South Korea. Tel: 82-53-620-1426. E-mail: yangjs@dnue.ac.kr
}

Received: July 27, 2017 Accepted: October 16, 2017 Online Published: October 19, 2017

doi: 10.5539/elt.v10n11p183 URL: http://doi.org/10.5539/elt.v10n11p183

\begin{abstract}
This case study explores the language attitudes and perceptions of Korean parents, with regard to their children's native language maintenance and ESL education in the US. The primary focuses are on (1) what aspects are held by Korean parents toward the maintenance of the native language in the US, and (2) how these perspectives operate in their children's language education. The data for this study includes autobiographies and in-depth interviews with two Korean mothers whose children attend a Korean language program at a Korean school in the US. The findings indicate three emerging issues, including native language maintenance, practices of language using, and identity formation. The elicited data underscores that English exceeds its meaning as a single language. For the parents, the English proficiency signifies prospective social outcomes (e.g., employment, wealth, and education) for their children's life in the future.
\end{abstract}

Keywords: language attitudes, language maintenance, identity, Korean parents, ESL

\section{Introduction}

Growing attention has been paid to the significance of heritage languages because they have been regarded as a personal, societal, and national resource, in terms of globalization (Brecht \& Ingold, 1998; Zhang \& Slaughter-Defoe, 2009). Due to the increasing number of immigrant groups, or those seeking university degrees in the US, scholarly interest on heritage languages has steadily grown. Of those immigrant groups, Korean are among the more recent groups to enter the US. According to the US Census, the number of Koreans living in the US reached over one million in 2000.

Since 1990, English education in Korea has been significantly growing under the government's project of 'globalization' in Korea (J. K. Park, 2009). Additionally the 'English fever' in Korea has led to both the early study abroad for young children, and English study abroad for student of all ages (Chung, 2008; Kim, 2006). Unlike those who live in Korea, Korean parents in an ESL setting are more likely to be exposed to multilingual or international environments. As second generation children grow up in a bilingual (but predominantly English) environment, the language shift between their native and English languages is being commonly observed (Edwards, 1994; Fillmore, 1991; Hornberger \& McKay, 2010). In the meantime, there is also a concern about the language choice dilemma for Korean children in the US (Hornberger \& McKay, 2010). When exposed to a bilingual environment, these children might lose their native language because of the relative dominance of the second language. Korean immigrants' patterns of using language indicate that the Korean language is exclusively used by the first generation of immigrants. On the other hand, English is dominantly used by most of the second generation of Korean Americans (Hurh \& Kim, 1984).

As Fillmore (1991) argues, with the danger of minority languages disappearing in the US, the maintenance of individuals' native languages have been increasingly highlighted. In light of this, Korean parents in the US seem to have a unique attitude toward bilingual education and their beliefs regarding second language acquisition of their children. They might be concerned about their children's loss of their native language, let alone with acquiring an English education. Kondo-Brown (2006), in investigating East Asian (i.e. Chinese, Japanese, and Korean) heritage language maintenance, suggested that heritage languages will disappear in the second and third generations, without the mainstream support. Considering such concerns, Korean parents need to focus their effort in getting their children involved in heritage cultural activities, and institutions such as Korean language schools or Korean Sunday schools. 
Moreover, due to the different socio-cultural contexts of a foreign country, the children of those Korean immigrant groups may encounter complex situations, and may struggle to adapt to new school settings. With regard to adolescence as a critical period of identity formation, children at this age are likely to absorb new social values, norms, and beliefs, while they change or re-formulate their pre-existing identity stemming from Korea. Drawing on Hall's (1990) approach to the formation of identity as an on-going process, identity is a "production which is never complete, rather than that which is already accomplished fact", identity is always in the process of formation (p.222). As the input of the parents plays a significant role in the development of their children's literacy and shaping their identities, the parents are- as a result- can provide the most reliable observations on the patterns of language loss or maintenance in their children. Thus, Korean parents' perspectives on their children's maintenance of mother tongue and English education in the US mirror emerging factors which are possibly germane to the dynamic process of re-constructing a new identity to address the changes in their life. This study, therefore, aims to look closely at the perspectives of Korean parents on the language instruction and learning for their children in the US. In particular, this study addresses the following questions:

1) What are the Korean parents' perspectives on the maintenance of native language and English education for their children?

2) How do these perspectives operate in their children's language education, and the development of their identities?

\section{Literature Review}

\subsection{Korea's English Language Education and English Fever}

Over the last few decades, owing to the unique phenomenon of English fever in Korea (Chung, 2008; Kim, 2006; J. K. Park, 2009), Korean parents-obsessed with their children's English education- have been spending a large amount of money on enabling their children to study English. Not only are the youth sent to private cram schools after school, but also they are even sent to English speaking countries, such as USA, Canada, or Australia, to name a few. Because of the parents' widely held myths of 'the younger, the better' with regard to second language acquisition, a large number of Korean parents have seen that having their children learn English in the US appears to be the best option in spite of substantial financial burden. In terms of the English fever in Korea, a large number of scholars have reported this unique phenomenon, with an aim toward finding out why increasing numbers of Korean children have been sent abroad to learn English, and how the current boom of English was founded.

J. K. Park (2009) argued that Korean English fever has its roots in the educational tradition, originating from Confucianism. This educational obsession has led to the preoccupation with English education in Korea. Since 1990, the significance of English education has been growing under the Korean government's "globalization" project. Along with the overwhelming stream of globalization, English education has been the one of the ultimate reasons for parents to send their children to the US. Moreover, the 'English fever', resulting from the traditional 'education fever' in Korea, has led to both the early study abroad of young children and the English study abroad of student of all ages (Kim, 2006; J. K. Park, 2009). English education has been regarded as one of the most powerful means to achieve the social and economic success in the global world. At school, English has steadily played more significant role than other subjects, such as Korean history, which becomes an optional subject for college entrance exams. Rather, English ability has partially become a symbol of higher socio-economic status, class background, and level of education.

In order to pursue both educational prospects and ESL education for their children, some parents take extreme measures- they attempt to give birth to their children while in the US, so that they can secure a US citizenship and thus, a better future (Becker, 2013). For some middle to upper class parents, getting a US citizenship for their children can also be a means of avoiding required military service for their children in Korea, while having access to cheaper or even free education as a US citizen (Choi, 2010-04-06). Moreover, the phenomenon of 'wild goose families' has created a source of social concern in Korea. The term "wild goose families" refers to a single parent staying in a foreign country, with their offspring, in order to secure an English education for them. In this case, the father typically stays behind in Korea for financial support. According to the Ministry of Education and Human Resources Development (2006), the number of elementary school students studying abroad has been drastically increasing. This report implies that the widespread phenomenon of English fever in Korea is still ongoing.

The role of mother is also pivotal in the children's English education in Korea. Park and Abelmann (2004) conducted an ethnographic study on the case of three Korean moms' management of their children, in regard to 
their English education. The research reflected how complex their English desires were, as expressed in their lives. Three mothers from distinct class positions (i.e., working-class, middle-class, and upper middle class) highlighted that cosmopolitan striving and achievement resulted in their social mobility toward the upper class. Their perceived desires were constructed to redress their frustrating past in the cosmopolitan society. The desires have been the driving force behind their children's English education, in that English could enhance their children's future.

Under these circumstances, the issue of the Korean ESL learner's identity becomes important, because they live in flexible and dynamic societies between the US and Korea. Identity is constructed by the desire for recognition, the desire for association, and the desire for protection (West, 1992). Interestingly, such desires- in the Korean context- have been closely related to the parents' desires, as well as those of children. Sorensen (1994) examined educational success in South Korea, with regard to socioeconomic contexts. Sorensen points out that strong family structures and the high valuation of education are significant factors of success. Social structures, parents and teachers are seen as active agents who are willing to make extraordinary commitments to the students.

\subsection{Identity Formation through English Language Learning}

Language plays a significant role in forming one's identity. As Norton (2000) argues, the multi-dimensional aspects of society, where L2 learners are involved, the issue of the L2 learners' identity construction can be considered in terms of L2 learning. Several studies explore how the second-language-learners' identity is constructed and reformulated through ESL learning (Ibrahim, 1999; Lam, 2004; Pomerantz, 2001). Lam (2004) especially focuses on the online space as being a place of language socialization, in terms of the ethnic identity of Chinese immigrant students in the US. Based on the process of language socialization, the author indicated the social and discursive patterns in an electronic space for Chinese participants. The findings show that diverse mixed-codes of English is employed and constructed among the participants and their peers around the world. Such process leads to constructing their relationships as bilinguals of English and Chinese. Lam's finding is meaningful in that even local practice of English, reflects that language variety serves to create a shared ethnic identity for young ESL learners and allows them to assume a new identity as a bilingual between Americans and Chinese in ESL context. In other words, their newly constructed identity in an online space affects their social status in ESL setting and their relationship with English.

Moreover, Ibrahim (1999) and Pomerantz (2001) especially focus on the classroom setting. Ibrahim (1999) conducted a critical ethnographic research at a Franco-Ontarian intermediate and high school. The participants were African youths, as the minority population at the school. The research illustrates a discursive space, which is imagined and constructed by the African ESL students. The socially imagined identity is reflected in the process of classification of their identities. Based on a social constructivism, Pomerantz (2001) examined the role of a Spanish learner as a foreign language learner in an advanced conversation course at a university in the US. Regarding the identity of the learner as complex and social entity whose identity is constructed within and through language, Pomerantz stipulated the identity construction and negotiation are processed across three levels of language use such as the institutional, interactional, and individual. The findings, based on discourse analysis, shows that the students' identities as language learners are articulated in the way they use language and interact in the classroom.

Studies by Lam (2004), Ibrahim (1999), and Pomerantz (2001), all of which focus on the language-learning context, reveal that the identity is constructed dynamically in the process of language learning. Because of the significant role of language in the process of identity formation, it is necessary for language learners to integrate learning into new socio-cultural contexts. As for Korean adolescent ESL learners, they encounter school institutions and classrooms that are far different from those in Korea. The new school environment is the focal area where the Korean young adults spend most of their time. While they learn English in the context of ESL (which is different from EFL in Korea) they become involved in the process of the privileging of new discourses- negotiating between a pre-existing identity and a new identity, reconstructing a new identity, and constructing collective identities between two different social contexts.

\section{Methods}

\subsection{Rationale: Research Sites and Participants}

\subsubsection{Korean Heritage Language School}

The Korean Heritage Language Schools has been holding classes in Korean language, culture, and history for any student interested in Korea since 1984. Usually, 7 or 8 classes or levels of Korean are offered, according to the students' Korean language skills. The class meets for two hours every Friday afternoon, after regular school 
is over; the school follows the same academic schedule of the local school district. Each class usually has about five to eight students. The school does not have a permanent building, but it uses space offered by local churches and institutions. Among the classes offered in the school, the class on Korean history is the only class whose main purpose is to teach not only the native language but also the social studies (i.e. Korean history). There are six students who take this course. The students range from the K-3 to the K-5 level. Their children have been in the US for one to ten years. In either of these time spans in the US, parents could observe their children in terms of their language use, between the Korean and English languages.

\subsection{Participants}

This study draws primarily from the qualitative data collected from two Korean mothers ('Moon' and 'Kim'pseudonyms have been used) having bilingual children in the US. Their children are enrolled at the Korean Heritage Language School. Both participants are well-educated university students, and are pursuing a graduate degree in education. Moon and Kim speak Korean as a native language; their children were either born in the US as a legal citizen, or came to the US as a foreign dependent.

Moon has a son who is in grade 4 in a public elementary public school in the US. She has lived in the US for about 14 years. Initially she was a housewife, living with her husband, who was a graduate student. Later on, however, she made a decision to study further about language education; she is a graduate student, pursuing a master's degree. She obtained a bachelor degree in Korea, majoring in special education. She has also been actively volunteering as a member of a choir at a Korean church. Her son has attended the Korean Heritage Language School.

The other participant, Kim, was in her mid-forties and had come to the US seeking a graduate degree in higher education. She lived in the US for about 3 years, and had two sons and a daughter. One of her two sons was in third grade in a public elementary school, while her other son and her daughter were attending high school. She was struggling, as a result of being both a student and a mother with three children to take care of. Kim obtained a BA and MA in English and English Literature from a university in Korea. Her husband lives in Korea, because he has a job there. Kim is a Christian, and is involved in various religious activities with her children, who attend Sunday school at a Korean church.

\subsection{Data Collection}

The data collection methods included in-depth interviews and autobiographical essays. The in-depth interviews are conducted on a monthly basis during the school semester. The most attention to address the research questions is paid to the data from the interview. Based on the previous research on ESL parents' attitudes to the children's second language learning, the interview questions are structured (Chung, 2008; Kim, 2006; Park, 2011; Zhang \& Slaughter-Defoe, 2009). The interviews were conducted in Korean, which both parents were comfortable to speak; the interviews were audio-recorded and transcribed. The transcription was encoded thematically, with regard to the issues relevant to the research questions and topics. Also, the emerging themes from the autobiographies were identified, and those topics were posed to both interviewees in order to elicit more expanded ideas.

\section{Results and Discussion}

The emerging issues from the data indicated three major themes: (1) heritage language maintenance, (2) personal belief about her child's language use (e.g. code mixing and code switching), and (3) identity formation.

\subsection{Maintenance of Heritage Language}

In regard to the Korean parent's belief and perceptions about her bilingual child's use of heritage language and practice at home, Moon thought that the maintenance of the native language (i.e. Korean) played a significant role in building the child's national identity as a Korean. In order to maintain the native language, Moon got her son involved in diverse Korean culture-oriented environments or activities (i.e. Korean Heritage Language School, Sunday school at a Korean church, and informal gatherings with other Korean peers). Additionally, she also made an effort to help him learn several Asian languages, such as Chinese and Japanese. Her understanding was that, when her child was exposed to diverse world languages, he could expand his range of understanding of the other people around the world. She also highlighted the importance of mutual understanding among the different races in the world. The overall data illustrated well her desire for her child to speak as many languages as possible in the globalized world.

Kim also noted she felt the maintenance of the native language seemed to be as important as English education in building her children's national identity as Korean. In order to maintain their native language, Kim's children have been involved in diverse Korean culture-oriented settings (i.e. Korean Heritage Language School, 
and Sunday school at a Korean church). Unlike Moon, Kim taught the Korean language to her youngest son at home, herself. She also tried to tell him bed time stories. She mentioned feeling that a Korean language education was more important for her children in the long term than English education, because she intended to return to Korea after graduation, and an English education was important for her children.

\subsection{Variety of Mixed-Codes}

With regard to the code-mixing and code-switching between their heritage language and English, generally Kim did not want her son to do both types of transitional language use practices, specifically in Korea. Based on her recollection of her experience, when her son visited Korea last year, he was teased by his peers because of the fact that he had a different accent than his Korean friends, and he mixed both English and Korean. On the one hand, Moon's son tended to use both code mixing and switching when he talked about what happened at school, such as informal conversation with peers, academic discourses from teachers, etc. Furthermore, recently she could see that her son seemed to lose Korean more and more, in that he often seemed to be confused about between Korean and English even when he used a simple word in Korean (e.g. 'head'). The frequency of his usage of English has been steadily increasing. Nevertheless, interestingly, he seldom spoke English when he talked to his sister and older brother. Moon's daughter and older son mainly used Korean.

Kim argued that people who obtain a higher education should not use code mixing and switching. Admittedly, she has frequently used code mixing and switching in the single-word or phrase level in the US when she has conversations with other Koreans. However, in Korea, the practice of code mixing on the adult level may cause uncomfortable relationships with the interlocutors. The code mixing or switching could be seen as an indirect way of showing off their personal background, including a higher socio-economic status or higher education from abroad.

Moon's report indicated her willingness to keep her son using both patterns of L1 and L2. Her negative opinion on code mixing and code switching resulted from a miscommunication within a peer relationship. In other words, the language use pattern of using both languages may negatively influence the peer relationship in both Korea and the US. From her reflections, it seemed that she was highly concerned about her child's exclusion from the mainstream community. This may reflect that social variables influence her language ideologies.

One of Moon's beliefs about her children's language use is about code-mixing and code-switching. Moon reported her child had used code-mixing and code-switching from time to time. His simultaneous use of the two languages is not random or arbitrary; rather, he has spoken Korean at home and communicated in this way with her mother. Most of the topics or issues were about what was going on his life. On the other hand, he mostly uses English when he tries to talk about what happens at school, and between US friends. She observed that her son used Korean when he had just come back from Korea last year. However, he seems to feel more comfortable to use English than to use Korean in everyday life. English is the language he uses mainly, when he talks about what he learned in school, with regard to academic words and concepts such as math terms, grammar, and vocabulary. In the short term, the code mixing and switching practice seems to be a useful and natural phase in language learning; on the other hand, the practice will not be helpful for him to learn both the second and the native language, in the long term. Furthermore, when she mentioned about her son getting teased by peers in Korea, she also expressed concern about the fact that the code mixing and switching could result in interpersonal conflicts within Korean society. In Korea, young children who speak English better than Korean may be viewed as those who are from rich family. On a deeper level, the peers in the mainstream society are likely to project their jealousy by bullying or teasing others who were from 'the haves'.

Likewise, Kim's perspective on code mixing and code switching was pessimistic, in that she did not want her children to keep using both patterns of L1 and L2. Her negative opinion resulted from concerns about miscommunication within a peer relationship. Ultimately her child's code mixing behavior may negatively influence his peer relationships in both Korea and the US. This may reflect that social variables influence her language ideologies. Further, she mentioned about her son switching codes, and that he did not always use English with his peers. When he was playing with a Korean friend who had just came to the US, he tried to use Korean. This is worth mentioning because I also observed Moon's son doing the same in the classroom. If a peer initiates a conversation in Korean, then other interlocutors use Korean, or vice versa. The children also conceptualize the proficiency or language usages of interlocutors while participating in conversation.

One of the significant issues of secondary schools in Korea can be exemplified from the above perspectives. The 'bullying' issue seems to be worth considering among adolescents, rather than college level students, because of their immature attitudes. 'Wangtta' is a phenomenon that refers to a certain majority of students excluding the minority students in the school (G. C. Park, 2011). There may be a numerous factors, such as socioeconomic 
gaps, personalities, and differences in speech or even appearance. Many of the victims of bullying have been marginalized only because of their being different from the students in the majority, not because of their being "wrong". This social effect influences the perspectives their parents have on the language use of their children, even if they thought code mixing and code switching are natural and have a positive effect on their children's language acquisition in the transitional period.

\subsection{Identity Formation}

Regarding national identity, Kim was really concerned about her son's struggles in the near future, with regard to the determination of his nationality. He has dual nationality until the age of 22 , because he was born in the US; however, once he reaches 22 , he will have to make a decision about his nationality. Her stand point with regard to this question was that her son is responsible for the decision for the rest of his life.

Finally, her opinion on the issue of overly passionate mothers was clear and determined. The mothers in Korea usually pushed their children to go to more than two after-school program for studying English because they ultimately aimed at having their kids admitted to the highest university or the most prestigious private high schools in Korea. She felt that nowadays, English language has been regarded not only as a language ability itself but also a standard of the students' general ability. Fluency in English could guarantee a better future, with a higher salary, better social reputation, or perhaps a promotion. She was initially against the social customs concerning learning English, but she admitted that it usually happened in Korean society.

Kim was really concerned about her son's struggles in the near future, with regard to the determination on his nationality. She admitted somewhat that there was a relation between language use and identity, but Kim did not think that the relationship between the two was close; it depended on how her children viewed themselves. Although her children might lose L1 completely, they might view themselves as Korean, and their desire to be Korean could be very high. Around the age for her son to make a decision on his nationality, Kim's stand point with regard to this question was that she will put effort to give her children every opportunity to be involved in Korean culture and society.

Based on the findings regarding a dual nationality of both Korean and American, a child born with two nationalities might suffer from having to decide between the two in the future, which is not as simple an issue as it might seem. In Korea, military service for males is mandatory. Because of this, a significant number of Korean parents intentionally give birth to their babies abroad, specifically in the US and Canada, in order to avoid the 2-year mandatory military service term after getting a foreign citizenship, to obtain an English education abroad, and to fully immigrate to these foreign countries. This study indicated that both parents were fully aware of this issue and argued against the bandwagon effect in Korea.

Even though they admitted that some aspects of Korean culture might influence their children's education or life, they were still proud to be Korean. What is more about the nationality, the parents wanted them to be Korean, but they admitted it all depended on their children's decisions upon reaching adulthood. Their perspective on their children's decision regarding their nationality was flexible and open-minded- it centered on accepting their children's decision. Also, the parents' educational experiences could have been influenced by diversely cultural experiences. Moreover, one of the interesting points of views on nationality indicates that- since the children stand between being Korean and being American- they could not be any of one pure nationality.

"He is not American and he is not even Korean, either. He seems to be somewhat an outsider around American friends and he also seems to be an outsider around Korean friends. I don't think this is not dichotomous. This is like a new kind of nationality in the next generation in the future."

\section{Conclusion}

This paper focuses on Korean parents' attitude toward English language education, and how they perceive their children's native and second language use in the US. The role of parents in Korea is as active participants, who are involved in the educational decisions of their children. Thus, those parent's voices play a critical role in children's literacy development. The elicited data from Korean parents whose children go to Korean Heritage Language School underscores that English exceeds its meaning as a single language. For the parents, the ability to speak English implies positive social outcomes (e.g., employment, wealth, and education). Furthermore, English is considered to be a "must have" language, in a cosmopolitan world-view. Finally, even though there were several different views on the children's use of code mixing and switching, the general consensus of the Korean participants in this study is that the use of code mixing and switching is acceptable and encourages their children's language learning or acquisition because this language practice is naturalistic and transitional. On a social level (specifically in Korea), however, those types of language practices might negatively influence their 
social interactions because fluency in English can be used to denote various social aspects.

\section{References}

Becker, D. J. (2013). Parents' attitudes toward their children's heritage language maintenance: The case of Korean immigrant parents in West Michigan. Masters Theses. 59. Retrived from http://scholarworks.gvsu.edu/theses/59

Brecht, R. D., \& Ingold, C. W. (1998). Tapping a national resource: Heritage languages in the United States. Washington, DC: ERIC Clearinghouse on Languages and Linguistics.

Choi, S. (2010-04-06). Overseas childbrith: Just a hop, skip, and a push away. Korea Herald. Retrieved from http://www.koreaherald.com/national/Detail.jsp?newsMLId=20050324000013

Chung, K. (2008). Korean English fever and temporary migration: Understanding Korean temporary migrant parents' desire and practices for their children's English education in the US. Paper presented at the South Korea's Education Exodus Conference. Urbana-Champaign, IL.

Ministry of Education and Human Resources Development. (2006). A statistical report of study abroad students who went abroad and returned during the 2005 school year.

Edwards, J. A. (1994). Multilingualism. London; New York: Routledge. https://doi.org/10.4324/9780203430927

Fillmore, L. W. (1991). When learning a second language means losing the first. Early Childhood Research Quarterly, 6(3), 323-346. https://doi.org/10.1016/S0885-2006(05)80059-6

Hall, S. (1990). Cultural identity and diaspora. In J. Rutherford (Ed.), Identity: Community, Culture, Difference. London: Lawrence \& Wishart.

Hoeffel, E. M., Rastogi, S., Kim, M. O., \& Shahid, H. (2010). The Asian Population: 2010. Retrieved from http://www.census.gov/prod/cen2010/briefs/c2010br-11.pdf

Hornberger, N., \& McKay, S. (2010). Sociolinguistics and Language Education Multilingual Matters. Washington, DC: Library of Congress.

Hurh, W. M., \& Kim, K. C. (1984). Adhesive sociocultural adaptation of Korean immigrants in the US: An alternative strategy of minority adaptation. International Migration Review, 188-216. https://doi.org/10.2307/2545947

Ibrahim, A. E. K. M. (1999). Becoming black: Rap and hip - hop, race, gender, identity, and the politics of ESL learning. TESOL Quarterly, 33(3), 349-369. https://doi.org/10.2307/3587669

Kim, Y. (2006). English fever in Korea: Impacts on the teaching of English and social issues that arise. The International Journal of Language, Society and Culture, 16(1), 337-350.

Kondo-Brown, K. (2006). Heritage language development: Focus on East Asian immigrants (Vol. 32): John Benjamins Publishing. https://doi.org/10.1075/sibil.32

Lam, W. S. (2004). Second language socialization in a bilingual chat room: Global and local considerations. Language, Learning \& Technology, 8(3), 44-66.

Norton, B. (2000). Identity and language learning: Gender, ethnicity and educational change: Longman London.

Park, G. C. (2011). Becoming a "model minority": Acquisition, construction and enactment of American identity for Korean immigrant students. The Urban Review, 43(5), 620-635. https://doi.org/10.1007/s11256-010-0164-8

Park, J. K. (2009). 'English fever' in South Korea: its history and symptoms. English Today, 25(01), 50-57. https://doi.org/10.1017/S026607840900008X

Park, S. J., \& Abelmann, N. (2004). Class and cosmopolitan striving: Mothers' management of english education in South Korea. Anthropological Quarterly, 77(4), 645-672. https://doi.org/10.1353/anq.2004.0063

Pomerantz, A. I. (2001). Beyond the good language learner: Ideology, identity, and investment in classroom foreign language learning. Dissertations available from ProQuest. AAI3003681. http://repository.upenn.edu/dissertations/AAI3003681

Sorensen, C. W. (1994). Success and education in South Korea. Comparative Education Review, 38(1), 10-35. https://doi.org/10.1086/447223 
U. S. Bureau of the Census. (2004). Census of the Population: 2000. Washington, DC: US Government Printing Office.

West, C. (1992). A matter of life and death. October, 61, 20-23. https://doi.org/10.2307/778781

Zhang, D., \& Slaughter-Defoe, D. (2009). Language attitudes and heritage language maintenance among Chinese immigrant families in the USA. Language, Culture and Curriculum, 22(2), 77-93. https://doi.org/10.1080/07908310902935940

\section{Copyrights}

Copyright for this article is retained by the author(s), with first publication rights granted to the journal.

This is an open-access article distributed under the terms and conditions of the Creative Commons Attribution license (http://creativecommons.org/licenses/by/4.0/). 